\title{
The Eclipsed Symbiosis of Aesthetics and Morality in The Benefactor*
}

\author{
NING Hui-xia \\ Henan University of Technology, Zhengzhou, China
}

\begin{abstract}
This essay expounds the indiscernible symbiosis that hitches formalist aesthetics to moral consciousness via an analysis of the fictionality of metafiction, the uncertainty of dream narrative, and Sontag's sarcasm of anti-intellectual behaviors imbedded in her novel The Benefactor. The fictive nature of the novel is well manifested via the pervasive disclosure of self referential narration made by Hippolyte. The glaring discrepancies between the dreamlike life experiences expatiated on by Hippolyte in the main body of the novel and the circumstances laid plain en masse in his journals, letter, and manuscript which come out at the close of the novel are a strikingly acute revelation to remind a reader of the novel of the uncertainty of Hippolyte's narration. The concluding section of the essay is an analysis of Sontag's satirical version of anti-intellectualism: She arranges for the two abnormal characters — one is fond of daydreaming, and the other is temperamentally "camp" — to revert to the normal way of life and become intellectually pedestrian. The conclusion of the novel obscurely implies that the realities of the world have rendered it difficult for such a moral disburdenment as is set forth in Sontag's aesthetic conceptualization to come into being.
\end{abstract}

Keywords: aesthetics, morality, the eclipsed symbiosis, The Benefactor

What is naturally to flash across our minds, whenever the name, Susan Sontag (1933-2004), is alluded to, the image of an outstanding contemporary American literary critic. People are wont to name her as "the dark lady of the American letters" (Podhoretz, 1968, p. 154). Compared with the sensation her essays have stirred up, her fictional works have not achieved the same stature. That is why critic circles are inclined to call her a literary and cultural essayist rather than a novelist. However, Sontag herself insists that her essays are not an adequate justification of the practice as a fictive writer; nor are her fictional works an illustration of ideas exemplified in her essays and films. She prefers believing "the energy, and the anxiety, that spilled over into criticism had a beginning and an end" (1966, p. ix). She was never content to cease in the realm where she could safely enjoy the accomplishments she had achieved, or accept the worship of her admiring readers.

The Benefactor $(T B)^{1}$, as Sontag's earliest fictional work, has stirred up a whole gamut of mixed responses.

\footnotetext{
* This research paper is based on the findings from the academic research program "Politics, Ethics and Aesthetics Prevailing in Susan Sontag's Literary Creation” (201509895004) funded by China Scholarship Council, and the research project "An Analytical Study of the Ethical Dimensions of the Three Aesthetic Paradigms as Demonstrated in Susan Sontag's Literary Creation" (2015SBS013) financed by Henan University of Technology's Doctoral Foundation.

NING Hui-xia, Ph.D., Associate Professor, teaching in the Foreign Languages School, Henan University of Technology, Zhengzhou, China.

${ }^{1}$ In this essay of mine, only the initial letters of each key word in the title of a fictive work by Sontag are taken; and such initial letters are put together to function as an abbreviation of the work in question. For example, the abbreviation $T B$ stands for The Benefactor. The abbreviation USS stands for Under the Sign of Saturn. The abbreviation AST stands for At the Same Time.
} 
This is readily perceivable in the following instance: Daniel Stern compared Sontag's work to the nouveau roman of her French colleagues, "the style of the novel concentrates on itself” (1963, p. 5). James Frakes called it "very special book, written with care, polish, daring, and certainty. Very sure and very tough" (1963, p. 10); yet he also took note of TB's "frustrating design", reckoning that "Sontag's absolute exclusion of insight squeezed life out of the novel. What she gained in purity of form, she lost in chapters that became monotonous" (1963, p. 10). Robert Adams appreciated Sontag's original depiction of "a mind lost in its own intricate dialectic” (1963, p. 19), but he also complained that Sontag lacked Voltaire’s wit or gift for comedy. Carl Rollyson spotted the resemblance between Kenneth Burke's Towards a Better life and TB. "Neal's language is 'pure artifice'; that is, it does not arise out of character development or plot. Instead, he is his arias as much as Hippolyte is his dreams" (Rollyson, 2001, p. 52), but he concludes that "what can be attractive as well as off-putting about this kind of self-contained fiction is that it is so ouvre” (Rollyson, 2001, p. 53). Sontag herself was inclined to admit its fictionality, reiterating the importance of form construction in her fictive writing. Form has always been an important concern in her fictive writing, and her meditation on the form of her fiction never recedes from her interest. Forty years later after the publication of $T B$, she readdresses her preference to the fictive writing in the preface specially written to the Chinese version of $T B$, "I clearly knew I wanted to write fictive stories and fictive characters. I did not want my writing to be restricted to my own story" (Sontag, 2007, p. ii) $)^{2}$. TB is a representative well presenting her concept of fictionality in fictional writing.

This essay is dedicated to tracing the relationship that combines aesthetics to morality. The analysis starts from analyzing the fictionality of Sontag's formalist aesthetics and how the overemphasis placed by Sontag on form in her literary writing serves to abate the intensity of her concern for content. It does not mean that thematic consideration along the moral line does not exist at all in $T B$. What is the crude actuality in this connection is that the thematic consideration along the moral line—so far as the novel $T B$ is concerned — cannot help being overshadowed by her indulgence in overworking the novel's aesthetic upswing. The approach Sontag adopted - right in the interim when she was contemplating the creation of $T B$ - for exploring the possible optimum form in which she was about to attire her first brainchild, $T B$, was actually based on the following three considerations: (1) how the metafictional techniques can best meet the requirement for fictionality; (2) how one version of Hippolyte's dream narrative dissolves the certainty of the other version of his dream narrative; (3) how the adoption of satire can most aptly throw light on her reticent moral appeal.

\section{Fictionality of Metafictional Construction}

The word "metafiction" was coined in 1970 by William H. Gass, an American critic and self-conscious novelist. Metafiction is required to discuss the relation between the arbitrary linguistic system and the world to which it refers. Specifically speaking, it is devoted to explore "the relationship between the world of fiction and the world outside the fiction" (Waugh, 1984, p. 3). The metafictional novels disclose the fictionality of novels through constantly presenting the process of textual construction herein. Hence, reality is not the center of these novels, but how to construct a fictive text through language. Metafiction clearly reflects the dissatisfaction with the conventional values and breakdown of the conventional creating paradigm.

The emergence of metafiction heralds not "a decline or a death" of fiction, but "a renewed vigor" (Waugh, 1984, p. 68). The subversiveness metafiction has revealed to the conventional mimesis theory imparts fiction in

\footnotetext{
2 The quotation cited here is borrowed from "Introduction" she wrote for the Chinese version of The Benefactor, a translated work done by Yao Junwei and published by Shanghai Translation Publishing House in 2007.
} 
its crisis period with a new vigor, meanwhile, echoing the radical Counter Culture Movement of the 1960s, which requires reformation and breaking down all the convention. In a sense, $T B$ attests to Sontag's support of the Counter Culture Movement by boldly experimenting on metafictional technique.

The novel $T B$ begins with a portrayal of Hippolyte's dilemma: He sets about reminiscing his past life, but before long he comes to realize that his life recollected in such a realistic manner does not agree with life actuality. And thus he deems that it is only possible for him to have his past life represented by means of discourses. The language he employs in giving a narrative account of his past life becomes a prison, from which eluding is hardly possible. The beginning of the novel unveils the problematic relationship between life and fiction. The significance of story itself is inferior to that of the technique by which the story is told. The novel begins with an explicit discussion that is arbitrary in nature: Hyppolyte, as the first-person narrator, repeatedly demonstrates his ambiguous way of thinking as he recounts his life spanning the past three decades.

I wish at the start to warn the reader that while I endeavor conscientiously to present a just selection of those events, it is with no more than the eye and mainly the ear of recollection. It is easier to endure than to change. But once one has changed, what was endured is hard to recall. (TB, 1963, p. 7)

Abiding by authenticity is the principle of Hyppolyte's narration, but he cannot help but to find the paradoxicality during his narration. He justifies the ambiguity by saying if one has changed, it will not be easy for him to endure his past memory. Therefore it increases the difficulty of recalling what really occurred in the past. As a narrator and writer of his story, he will stick to his responsibility of "telling the truth". In order to humor his readers, he also mentions that he needs to consider "the character and preoccupations of my readers" (TB, 1963, p. 12). However, it seems that pleasing his readers is contradictory to persisting in telling the truth. Ultimately, he determines that "I shall try henceforth not to imagine who that someone else is, and whether he or she is reading what I have written" (TB, 1963, p. 12). But the more he emphasizes the importance of "telling the truth", the more he intensifies the challenge of transposing his life into narrative. Beyond this, Sontag seems to intentionally clarify that readers can freely take part in the game of deciphering by saying that "one must allow his reader his liberty, viz., his liberty to contradict what is written, his liberty to be distracted by alternatives" (TB, 1963, p. 12). No matter it is from the coding of a writer or to the decoding of the reader concerned, metafictional novels incessantly testify to the fact that the construction of them is to build up a maze of language. Writers can automatically explore fictiveness of novels; likewise, readers can make various interpretations from different perspectives. Just as Hippolyte declares in the beginning of his narration that he welcomes to establish a conversational relationship with his reader:

I omit the name of this city not to tease the reader-for I have not excised from this narrative certain words and the names of local institutions known to every would-be tourist, so that the reader will soon be able to identify in which city I lived-but because I wish to indicate my conviction that where I lived was not of importance in the matters I shall relate. (TB, 1963, p. 3)

The pervasive revelation done by the narrator in the beginning of this novel is meant for impressing upon its readers an aura of fictionality. Except for such contradiction of self-reflection as is reflected in language expression, uncertainty in metafictional novels is likewise reflected in the collapse of narrative frame.

\section{Uncertainty of Dream Narrative}

In $T B$, the dreams Hippolyte had in his youth constitute the overt framework of the novel. These dreams 
have no inherent correction and the content of the dreams is absurd, staying far away from the ordinary life. Sontag seems deliberately to eschew issues arising from the realistic conventions. Time and space are just vaguely identified in instances such as prewar Paris. The growing circumstance of the hero is diminished to fewer facts. What is important for a realistic novel is no longer as important as it should be in a metafictional novel. The questioning of the assumed reality makes a metafictional work keep close to life and authentically records ambiguity that crops up in life and in a writer's creation.

The story of $T B$ is ushered in by the scene in which Hippolyte gives an account of his life experiences; the scene is a narrative situation where the distinction between experiencing-I and narrating-I is particularly evident. As experiencing-I, Hippolyte is persistently exploring the essence of his dream: He has once attempted to fashion his life in line with his dreams; then he abandons it and goes to interpret them in terms of real life. Later on he concedes to have them interpreted on their own. Ultimately he attains the hundred-percent freedom of his consciousness by landing in a state of stark insanity. The novel concludes with the denouement where Hippolyte gives up dreaming and resumes his social inanity. As narrating-I, he now finds his mental peace and decides to look back at the tribulations of his consciousness befalling him in the past 30 years. This should be counted as the frame story of $T B$. However, his disputable mentality poses questions to the account he has given of his life and dismisses it as riddled with sinister suspense. As for Hippolyte's reminiscence of his past life, there are two different versions. One version says that as Hippolyte has been invited to Frau Anders's Salon because of a philosophical essay he writes, he decides to quit his college career so that he can focus on carrying on a pleasurable and trivial parley. From then on, he indulges himself in a serial dream. His first dream going by the name of "the dream of two rooms" serves to fashion the themes of his other dreams. In his first dream he can be seen being tortured by a sadist habitually wearing a black swimming suit. In terror, he flees into the other room; there he meets a lady in white. Fascinated by her beauty, he endeavors to please her but fails. In the subsequent dreams, the sadist and the lady constantly transform their outward appearances, but the physical and spiritual tortures inflicted on him have never ceased. In order to unlock the mystery of his dream, Hippolyte accepts the suggestion of Jean Jacque who has been successively a writer, boxer, homosexual prostitute and transvestite and, though having tried to live his dream out in real life, just finds out that the dream is anything but an end in itself, or rather, a preclude to more dreams. The sexual charged scenario in "the two rooms dream" incites Hippolyte to initiate a new project-the seduction of Frau Anders, for he assumes the white lady in dream is the incarnation of Frau Anders. If he can successfully lure her, the mystery to which he is confined will be resolved. He successfully seduces her to accompany him to start an exotic journey, during which he drugs her and directs her to perform the scene in dream, but disappointedly finds out that her submission can contribute nothing to interpreting his dream. Dreams are unduplicative at all. Trying to dispose of her, he sells her to a barman before he returns complacently to the capital. Years have elapsed when Frau Anders comes back, looking severely deformed and having been chasing after him for a life arrangement. Under the instruction he has elicited from his dream, he burns down the shelter in which she is staying. But she miraculously resurrects, demanding a marriage with him. Hippolyte bequeaths the big house he has inherited from his father to her and marries another provincial girl. He flees from her, after she has caught him in her hunt. She cohabits with him and his wife, and hides herself in their basement during the war to avert Nazi persecution. After the war was over, his wife died. Then he moves into the big house; and she has become a subdued lifeless woman, a ghost. 
But this recollection is immediately replaced by another, in which Frau Anders returns triumphantly, not as a victim but as a champion. She has reversed her miserable fate: She is acclaimed to the rulership of a village and finally succeeds in leading the villagers to prosperity and happiness, albeit she is sold to a barman by Hippolyte and then transferred among men. After a voluntary abdication, she comes down for taking her revenge and evicts Hippolyte from his mansion. This version of life is diametrically different from his other version of the dream.

The mushrooming of all the suspenses is associated with his mentality. Hippolyte seems vexed for failing to find out which one is the truth. He is not sure of the sequence of events. One of his friends accidentally referring to his detention in a mental institution is enough to arouse his suspicion as to his sanity once again. His undated notes, letters, and journals complicate his originally confusing consciousness. In no time is challenged the truth he recounts relating to the two versions of his former life experience. Hippolyte's intrusions via note and letter of regular frame, instead of reinforcing a continuous sense of reality, in effect, is to spill it open, and to expose the illusion of narrative. The draft for his present narrative is more like an account of his life than that of his dreams. Some information alluded in an undated letter, coincides with the information offered by the draft. Both dramatize the nightmare experience that he was kidnapped and incarcerated. The chief kidnapper is a lamb, treating him without mercy, his mistress he fell in love with rejected him. The letter, without a salutation, briefly recounts his life story utilizing the details and fragments from his dreams as autobiographic sources. Ransomed by his father, he continues to be plagued by his dream. An eccentric writer persistently appears in his dream. He sinks into perversity and debauchery. At an unconventional party, he almost rapes his hostess before the guests. Irritated by the loss of good feelings, he seeks religious counsel but is publicly humiliated. He tries the ministration of a psychiatrist; still it does not work. Whatever he relates is called into question. Facts he is certain of are illusions. While any "unreliable" conviction he has ever heard of turns out to be a fact. Thus what occurs in dreams is just the real life he has experienced. Dream and reality are reversed since the very beginning. At one time, his dream seems to be splitting with his real life but gets mixed up with it at another time. The unaccountable life lasting for six years in the big house turns out to be the stint of his detention in the mental institution.

Ambiguity and antithesis in the language resorted to in the novel imbue the novel's concluding part with the tenor of a language juggling. The game in language further intensifies the uncertainty of Hippolyte's dream narrative. At the end of the novel, we find Hippolyte encounters for the first time in his life embarrassing congratulations on his recovery from the mental disorder, though he does not think it important to confirm or to deny his ailment. Sontag actually intended to make the reader become aware of Hippolyte having come down with some infirmity by means of the ambiguity which his conversation bluntly imparts:

On the one hand, there was the fact that my memory, for the most part excellent, told me differently: I had not been in any institution, but in the house which I had inherited from my father, pursuing my solitude and the resolution of my dreams. On the other hand, as I have already explained, my memory does fail me on one important point. Moreover there are certain letters and journals which challenge my memory in its entirety. Perhaps it would be best for me to present some excepts from these and leave the reader to decide for himself. (TB, 1963, p. 264)

The moment when he firmly believes he has reliably grasped the knowledge of something, there would simultaneously flash across his mind some doubt as to the validity of the knowledge. His habitual cogitative vacillation usually renders him miserably confounded. Apart from opposition constructed by the prepositional phrases, the negations of the negated statements are effectuated through the use of coordinating conjunction 
word "but". "At one time I even doubt that I wrote it. But it is definitely in my handwriting, although occasional blottings and crossings out of the words indicate that I wrote in a condition of some strain" (TB, 1963, p. 265). Such examples can also be found in a draft for a novel he is working on. He even intends to use "Don't Believe Everything You Read" (TB, 1963, p. 265) as the title of the novel he intends to write. He is keenly aware of his cogitative vacillation and craves that his readers would help with unknotting the myth. And such a craving of his can only intensify the tenor of language game. In a sense, it is more convincing to assert that the storyline of a metafictional work tends to play a role very much lesser than that played the work's narrative techniques. So far as plot goes, storyline has to bow to its writing technique.

In 1974 while interviewed by Joe David Bellamy, Sontag said, TB contains "systematically obscure element ... because I want to leave several possible readings open” (Bellamy, 1995, p. 44). Like all dreams, Hippolyte's dream contains unresolvable elements and incidents that cannot be reduced to a definite interpretation. In such a sense, Sontag seemed to deliberately construct a fiction that defies interpretation by disturbing the conventionally dialectical relation between dream and life.

As an avant-garde experimental novel, the innovation embodied in $T B$ is not only reflected through an experimental transformation of the discourse mode; but in the dissolution of the certainty of plot. Definitely speaking, it is achieved through the pervasive disclosure of narrative voice and the expectation for conversation between the narrator and his readers. The development of plot never ceases at a point, but is full of distinct contradiction. There is no apparent distinction between the real and the fictive. What is assured of reality turns out to be illusion of dream. During the back-and-forth movement between reality and dream, certainty is dissolved, and uncertainty is the eternal state preserved as author's aspiration.

\section{Moral Disburdenment and Futility of Its Disburdenment}

Behind the aesthetics presenting in the form of metafiction is revealed Sontag's advocacy for moral disburdenment. In order to spare the readers from making judgment from moral criticism, Sontag intentionally builds up a structural maze, having her readers engaged in unknotting the entanglement of dream-and-reality. In the fictional work, dream is foregrounded; reality transformed into background receding. As a subconscious or unconscious activity, dream per se is difficult to understand. What's more, dreams in $T B$, are presented in absurdity: Each dream Hippolyte makes has no inherent and logical connection, and each deviates itself from the daily life. If her readers attempt to excavate some hidden connection between the thirteen dreams, it will be exhausting and frustrating a task. Sontag is not intended to convey clear-cut information. Absurdity of these dreams determines the impossibility of making a logical interpretation in accordance to the common sense. Furthermore, Sontag, via her narrator Hippolyte, expresses her position of refusing to make interpretation by virtue of moral criteria. It must be admitted that on his way to self-deletion, Hippolyte frequently encounters some moral or immoral choices, but evaluation of Hippolyte's amoral behavior is the least of Sontag's concern. Like her hero Hippolyte who is so obsessed with his dream, Sontag is similarly obsessed with building up a nominal maze for her fictional writing; therefore, she stubbornly refused to make an explicit comment on Hippolyte's amoral behavior or Jean-Jacque's wild and loose life. Her stance on the moral issues in fictional works can be perceived by her conviction stated in her essay "On Style", in which she emphasizes her different responses to transgression in mind and that in life.

Of course, we never have a purely aesthetic response to works of art...But neither would it be appropriate for us to make a moral response to something in a work of art in the same sense that we do to an act in real life. I would 
undoubtedly be indignant if someone I knew has murdered his wife and got away with it (psychologically, legally), but I can hardly become indignant, as many critics seem to be, when the hero of Norman Mailer's An American Dream murders his wife and goes unpunished. ...The point may seem obvious, but the prevalence of genteel-moralistic judgments in contemporary literary (and film) criticism makes it worth repeating a number of times. (Sontag, 1966d, p. 23)

Moral transgression described in literary works may not stir up the same indignation as that occurred in the real life. A writer needs to defend the autonomy of the aesthetic imagination, paying more attention to the aesthetic pleasure, other than being annoyed by the morality transgression in a fictional works. Therefore, it is vital for readers to understand that Hippolite's abnormal sexual behavior and crimes he commits are driven or enlightened by the dreams he had. They have nothing to do with his moral outlook. He would live out his dreams; totally ignorant of the discipline ethics has levied on his behavior in real life. The amoral disposal of the moral issues in this novel has nothing to do with morality itself; it is just the requirement of artistic creation.

It does not mean Hippolyte has never experienced conflict between morality and conscience over the right or the wrong of his behavior. It is the quest to detect the essence of dream that drives him involved in more dreams, up to total indifference to the hurt that his behavior might bring to others. If his behaviors of seducing Frau Anders make him feel unease at first, and then the feeling of guilt submits to his desire to fulfill dreams. When he makes the decision to abandon her, he justifies his behavior by saying it is for her erotic fulfillment. His self-beneficial behavior becomes altruistic according to his logic. These incredible and irrational behaviors, in effect, do not provoke readers into much anger; instead, his addiction to dream and resolution to live out his dream in real life fascinate us. The response we produce to literary works makes us know that we are engaged in the fictive world together with Hippolyte, rather than that we are witnessing Hippolyte commit these horrifying crimes in the real world. His possession in dream enables us to have abundant reason to believe it is just the processing of art imposed on life.

The purpose of his dreams does not consist in directing him to fulfill a dreamed life, but in purging himself from the impurity of his consciousness. Dreams, in essence, serve as the exaltation of spirit. It also has to be clarified that his rescue of Frau Anders and sequent bequeathing has nothing to do with the recovery of his conscience. It is a line of behavior helping him purge himself of the impurity of material life. Therefore, Hippolyte's possession in dreams is equivalent to the radical requirement of modern art for nihilism. Art is no longer required to imitate reality, but evolves into pure art pursuing self-representation. Hence his moral disburdenment is viewed as a quest for ultimate freedom from material world by virtue of radically emptying out one's former life. Moral teaching is repudiated by Sontag with contempt. Her efforts to defend art have its aesthetic space. Sontag revamped the conventional concepts of aesthetic pleasure and style existing for the new sensibility art. In "On Style" she argued that art is never historically and epistemologically innocent, the knowledge it imparts "is an experience of the form or style of knowing something, rather than a knowledge of something (like a fact or a moral judgment) in itself” (Sontag, 1966d, p. 22). She is not the first to expound the aesthetic function of art, but what posits her to such a privileged position in cultural criticism is the fact that she emphasizes art is embodied with its own life independent from interpretation that makes a text intelligible by disclosing its "true" meaning.

The publication of $T B$ immediately provoked the criticism from the New York Intellectuals; Lionel Trilling was skeptical of the recording of human consciousness in modernist writings, insisting on claiming the social and moral bearing of consciousness as its central attention. He also claimed that the modernist writings are determined to explore the unconsciousness of the isolated self in an attempt to locate and establish another 
form of reality beyond that of the contemporary social life. Modernist writers compel the commitment to a diverged idea - "the idea of giving oneself up to the point of self-destruction, or surrendering oneself to experience without regard to self-interest or conventional morality” (Trilling, 1978, p. 10). The freedom they sought from society "detaches the reader from the habits of thinking and feeling that a large society impose" (Trillling, 1978, p. xii). In light of his analysis, Trilling affirmed that the modernist writers disregard the significance of moral teaching, over-concentrated on narrating the morbid consciousness. Apparently it is a cultural snobbishness by delimiting a paradigm for literary creation so as to separate the modernist works from mainstream works which bear a social and moral significance.

\section{Sontag's Contradictory Attitude Toward Anti-Intellectualism}

Ignorant of morality per se is an inclination to morality. By averting the admonishment of morality in literary creation, Sontag clarifies her unconventional attitude towards moral issues in fictional creation. Sontag's overemphasis of "aesthetic form" does not mean there is an absence of moral concern in her works. Even in her earliest fictional work $T B$, her reflection on moral issues still exists. The reason why critics would dismiss her as a besotted aesthete is that her contemplation on morality is temporarily eclipsed by her emphasis on form construction. The first impression that $T B$ is apt to impart is the intellectual challenge the novel poses to its readers. Together with the pleasure of challenge is concomitant with the pleasure of reading-pleasure to be elicited from successfully decoding its complicated and maze-like form, rather than from the elusive moral implication seemingly inherent in the text. The novel is seemingly exploring the morality disburdenment through scrutinizing the construction of its radical form which lurks actually behind the metafictional form and the narrative of the different versions of dream. In this Sontag inadvertently reveals her dissatisfaction with the move of anti-intellectualism of the 1960s. As she stated in an interview:

We live in a culture in which intelligence is denied relevance altogether, in a search for radical innocence, or is defended as an instrument of authority and repression. As for me, the only intelligence worth defending is critical, dialectical, skeptical, desimplifying. (Cott, 1995, p. 107)

The Counter Culture Movement occurring in the 1960s has cleared off the intellectual components of the "high culture" when it proclaimed its rupture with all the past cultural heritages and vowed to destroy the out-of-date cultural conception. It is under such a cultural circumstance that $T B$ was created. Sontag was horrified by the anti-intellectualism of the movement, and of the bright-thinking people with whom she had stood side by side in various political situations, but she could not stand the anti-intellectual behavior they launched. Her discontent with the anti-intellectualism was acutely manifested in her attitude toward the two abnormal characters, Hippolyte and Jean Jacques in TB. They both live out of the conventional value and conception, and they both reflect a distinctly different temperament from the ordinary people.

Just she would like to establish a concept of moral disburdenment via the deliberate construction of fictive form so as to avert the over-interpretation of the content. The construction of metaficiton and the dissolution of dream narrative in $T B$ help her realize such a conception. Her meditation on the other cultural phenomenon in the Counter Culture Movement - the prevalence of anti-intellectualism - is activated through the use of irony in the other clue of plot. Compared with the distinct metafictional technique, moral components conveyed through irony increase the difficulty of detection, or rather, irony per se is tainted with deception. Hence, it should not follow the regular thinking pattern to comprehend Sontag's moral disburdenment. 
Hippolyte, in the fictional work, is the representative of intelligentsia. In order to search for freedom of consciousness, he does not grudge erasing his personality in reality. His possession in dream wins him Sontag's recognition. However, the concluding part of $T B$ is full of contradiction. Sontag fulfills Hippolyte's expectation for consciousness freedom, but intentionally makes him go insane. And his peacefulness is realized through detention to the sanitary asylum and de-consciousness therapy. His release is at the premise of giving up intellectual thinking. Hippolyte no longer stumbles into dreams and takes fancy to some harmless philanthropies, whereas Jean Jacque, elected to the Academy, is happy to go along with the then mainstream writing. The novel ends with intellectual absurdity redoubled by intellectual commonness. The irony, applied to the construction of plot served to pave the way for and facilitated the emergence of Sontag's irony levelled at the anti-intellectual denouement.

Hippolyte insists that his dreams are all the dialogue with self. Under the beckoning of his dream, he becomes addicted to the freedom of consciousness which cannot be the same thing as freedom and should rather be called eccentricity. But for him, it is a life helping him accomplish the real freedom. Ironically, Hippolyte comes to realize that one has to go insane while addressing himself to searching for his true freedom. There is no absolute balance between dream and reality: Either one chooses life and abandons the quest for dream, or one chooses dream and quits living a real life. Unless one can eradicate the slavery imposed by reason, he cannot be expected to achieve the ultimate freedom of consciousness in a secular society. In this sense, Hippolyte has emerged triumphant, as he dares to defy conventional disciplines, undaunted in his pursuit of freedom. His victory amounts to a conquest achieved by an individual over a communal will.

Hippolyte is released from the insane asylum on the condition that he gives up dreaming and resumes his intrinsic sanity. What is astoundingly ludicrous is the arrangement which bestows on him a philanthropic mode of life; and thereby he lives contentedly as he "enjoys the waning tribulations of subjectivity and the repose of a privacy” (TB, 1963, p. 274). That Hippolyte can acquit himself apparently without a hitch under those circumstances is indebted to his submission to his being emptied and dissolved. And his servility in surrendering his consciousness is in fact a ransom for redeeming his physical freedom. This can be testified by the following passage from the novel:

We cure the insane. We quiet the perturbed. I am more quiet now. More than quiet, I should say. I am fulfilled. For the true test of fulfillment is silence_-as the meaning of fulfillment is not being filled, but becoming empty. Dreams filled my mind, I emptied them out... To execute an intention amounts to abolishing a desire. The advent of anything brings with it mainly the problem of its disburdenment, its dissolution. The only thing remarkable about me is that I approached this task more comprehensively than most people do, thereby also narrowing my life more than most people care to do. For me, the very advent of myself suggested the problem of my own dissolution. (TB, 1963, pp. 272-273)

Were Hippolyte not kept in detention, and were he not forced to accept the condition that he be never freed from custody until he give up reverting to baneful dreams? Can it be imagined that he would be led to blandly make suchlike deals? Sontag is quite at variance with the suggestion that power can really subjugate and enslave will. This can be testified by the passage cited below of Hippolyte's bold assertion:

I discover, with relief, that being good prohibits my dallying with the "interesting." Since I no longer dream, there is little that I find interesting about myself. Only other people interest me and I allow myself the pleasure of helping them. (TB, 1963, p. 263) 
Hippolyte's confession is self-contradictory: The internal peace is, in essence, the discovery of his new life being uninteresting. The pity Sontag has addressed to Hippolyte for the loss of intellectualism is implicit; or at least, she is reluctant to make a direct comment on the virtuous life Hippolyte is now living. In his new personality, he is indeed "the man without qualities", or rather the man from whom qualities have been erased.

Hippolyte is an artistic figure of Antonio Artrard, whose whole life is imbued with a history of suffering and agony from mental disorder. Cast into psychological asylum for over 10 years and imposed upon with numerous inhuman therapies, he was even inflicted with electric shock in the worst time of breakdown of his nerves. Although subjected to a series of affliction in life, he creates considerable dramas, and his ideas on play-writing are innovative and enlightening for later playwrights. It is fair to say that his life agony contributes to the fashioning of an extinguished dramatist. Agony supplies inspiration for the act of writing; the extreme mental or physical pain stimulates his passion for writing. From the perspective of pursuing consciousness freedom, Hippolyte can be seen as a miniature Antonio Artard. However, when confronted with the secular suppression inflicted upon their esoteric thoughts, either of them makes a choice quite varied from that the other does. The former abandons his consciousness freedom in exchange for physical freedom, while the latter demonstrates a heroic boldness and persists in pressing for his pursuit. Sontag is ironic to Hippolyte's submission.

Behind Hippolyte's perturbed consciousness, we can readily hearken to such a faint avowal as gives voice to an eerie speculation about the dream that is forthcoming:

Who knows if a new series of dreams may not someday be forthcoming, which will launch me on a series of speculations far different from those which I have experienced? Without expectations then, either of end or new beginning, I continue to live the life that is permitted me. (TB, 1963, p. 274)

The way Sontag was brought to succumb to Hippolyte can hardly be expected to elude sarcasm, as she envisaged that he could never survive either recovery in him of peace of mind or non-occurrence in him of any dream. In her essay entitled "Approaching to Artard", Sontag elaborates on her own definition of the term "madness" which she vows should be duly regarded as "part of the history of thought"; and she maintains that variation of the meaning of the term "madness" depends entirely on "how a given culture defines sense and seriousness; the definition has varied widely through history" (USS, 1980, p. 64). When a behavior becomes sufficiently individual, it may be regarded by others as anti-social or heretical. Hippolyte's madness is, to some degree, just some specific aspects of personal behavior when he is obsessed with deciphering the mystery that envelops "self". And it is precisely when he is thus preoccupied that he sinks deep into the reverie of being trapped in incarceration. As a matter of fact, he has neither committed any misdeed nor posed any threat to society; the alleged crime of murder or arson is nothing but outgrowth of hallucination which is kindled in his stupor brewed out of a rippling bout of solipsism.

It is Sontag who came to reveal the fact that there does exist a natural affinity between genius and madness in a great number of peak geniuses in history, such as Holderlin, Neval, Nietzsche, Von Gogh, Artard, especially when they lived in isolation from ordinary social life. And the madness in such extraordinarily gifted people is actually "the outward sign of a profound spiritual exile" (USS, 1980, p. 66). Sontag extolled these geniuses as "the heroes and martyrs of thought" (ibid), who were stranded at the vantage points of extreme social alienation, but volunteered for madness rather than for forfeiting a certain lucidity and passion for presenting their conviction. To imprison the intellectually demented is tantamount to suppressing the outbreak 
of distinguished intellectuality and wisdom. Who can deny that Sontag's holding anti-intellectualism in derision was not actually motivated by her desire to enunciate her own moral stand by way of the plot of her long novel? The devices such as self-reference, wordplay are Sontag's means to acquaint her readership with the facts that fiction can shake itself free of the duty formerly imposed upon it that it is obligatory for a fictional work to imitate the real life and that fiction can be such a literary creation as is completely a favorite game indulged in by a novelist. So long as a fictional work is nothing but a wordplay, it goes without saying that a wordplay defies any attempt at monopolizing neither its interpretation nor the criterion for determining its value.

Sontag's notion of moral disburdenment plus futility of moral disburdenment can further be perceived in another eccentric character, whom she portrays in $T B$-namely, Jean-Jacques - in who are incorporated multiple identities. And his regular identity in daytime is writer. One of his penchants is collecting odd goods, such as dandyish costume, picture postcard, newspaper clippings about prize-fighters and wrestlers, autographed photos of film stars, and confidential police reports. In eventide he chooses to exhibit his anti-conventional aspects. His methods of challenging convention are through incessantly changing his outward appearance in everyday life: Sometime he is in the apparel of a homosexual prostitute soliciting in the dark street. And the partner he would opt for his company on such an occasion ought to look impressively masculine in a sadistic way. But on another occasion he would behave in such an obtrusively masculinized way as to intrusively offer chaperonage to anybody he chances to swoop on. He even tries to cajole Hippolyte into abandoning his solemn vow of morality. As for his homosexual desire, he would champions for such an anti-conventional behavior in a most fulsome manner, saying that "homosexuality, you see, is a kind of playfulness with masks. Try it and you will see how it induces a welcome detachment from yourself” (TB, 1963, p. 57).

Although both Hippolyte and Jean-Jacques are non-conformists, they differ markedly from each other in the way either scuffles against social convention. The former desperately seeks to clutch consciousness freedom, whereas the latter flails wildly to shatter the constraint imposed by social convention on personal behavioral license. Towards Jean-Jacques's weirdness and associability, it is evidently Sontag's philosophical preference that induces her to take the attitude of moral neutrality. Or rather, she cherished mixed feelings in the face of the living style of either of the two characters, which can be attested to in a passage contained in her thunder-striking essay “On Camp”:

I am strongly drawn to Camp, and almost as strongly offended by it. That is why I want to talk about it, and why I can. For no one who wholeheartedly shares in a given sensibility can analyze it; he can only, whatever his intention, exhibit it. To name a sensibility, to draw its contours and to recount its history, requires a deep sensibility modified by revulsion. (Sontag, 1966a, p. 276)

Sontag even juxtaposes the sensibility "camp” art stipulates together with the other sensibility associated with the high art and the popular art. Being different from Hippolyte's conscious confrontation with the settled thinking pattern, Jean-Jacque directly revolts against the discipline imposed by society upon an individual. He features another embodiment of intellectualism. His anti-social demeanor also experiences a transmogrification in the end. But, rather than Sontag, it is Hippolyte who detects his own alterations through his indirect observation of him. What is particularly worth mentioning is this: Jean-Jacques's changes are something beyond Hippolyte's comprehension. Hippolyte is no longer his previous self who was addicted to dreaming 
weird dreams and to wildly interpreting them. He accidentally runs into a news report telling that Jean-Jacques has been elected to fill the post of Academie; aside the news carries a photo of Jean-Jacques. "In the picture he was grizzled, well-dressed, and puffy eyed” (TB, 1963, p. 260). But for the pair of eyes in the picture, Hippolyte would not be so sure of the identity of the person in the picture. But even the two telltale eyes in the picture are conspicuous enough—so it seems to Hippolyte-to indicate that Jean-Jacques has already undergone some stunning changes in his life:

And when I study the picture I ask myself, where is he? The great bully, the charming liar, the inconstant friend, the unprincipled coquette who amuse and taunted me in my younger days, the frivolous Virgil who watched me descend into the inferno of my dreams. He is gone: aged, transfixed by the great stare of the public eye, frozen. Now he is utterly famous. Everyone laughs at his mockery, he can offend no one. His acts have been transformed into postures, but not out of his own will and in the privacy of his intimate life. (TB, 1963, p. 260)

Hippolyte remains quite unperturbed about the changes taking place in himself but feels nonplussed about the changes that are perceptible in Jean-Jacque. He shows his contempt for him, despising his rejection of the "camp taste" in the course of gratifying his frantic ambition. Hippolyte cannot tolerate Jacques's apostasy. Through a graphic delineation of the interrelation and interaction between these two characters, Sontag imparts her disapproval of and repulsion against the social trend of consigning intellectual life to inferno.

Just the prototype of Hippolyte in $T B$ is the playwright Antonio Artard, Jean-Jacque that of Jean Genet, whose identity is a French writer in the novel. Born in poverty, Genet has frequented prison for a series of charges such as theft, vagabondage, lewd acts, to mention but a few. In 1949, he was even threatened with a life sentence by virtue of the 10 earlier convictions. The proposed life sentence was finally put aside because Jean-Paul Satre and other prominent social figures petitioned at that time to the French president for mercy in favor of the reprobate; and the latter vouchsafed to grant the petition and to interfere. Genet is regarded as a monstrous figure, moving about real and surreal at the same time. But his intellectual talent which is manifested in his literary creation as well as his eldritch conceptualization and theorization in philosophical realm has won him wide recognition. Satre acclaims him "Saint Genet". Jacques and Genet have a lot in common: The two alike lead a perverted life; both are talented in doing writings that glorify sexual perversion and moral degradation. However between them there are stark antipodal temperamental features. Genet never reconciles with social discipline, so he never loses his creating aspiration whereas as Jacque submits himself to conventional values and virtually negates the quintessence of "camp taste", which entails a total drainage of his creativity as a writer.

Hippolyte's rebellion is confined to the demesne of his quest for consciousness freedom. By contrast, Jacque's rebellion is achieved by virtue of his transgression upon the discipline of morality in a secular sense. Although their personal behavior does not pose a threat to the social systems in which they live, yet their intellectual eccentricity succumbs in fine to intellectual philistinism in their day. By making a comparison of one pair of the intellectuals with the other pair, Sontag voices her denunciation of the then anti-intellectual behavior. There is no established scientific norm, on the basis of which the dialectical relation between sanity and insanity, or that between eccentricity and mediocrity, can be duly worked out. Otherwise the heterodox voices would definitely have been silenced. If we are to designate an artificial frontier between the dialectical relations, we will definitely silence the heterodox voices, as Sontag once reasoned to that effect to one of her interviewers: 
We have to allow not only for marginal people and states of consciousness, but also for the unusual or the deviant. I'm all for deviants. There's no reason for people on this planet to live at a subsistence level. Instead of becoming more and more bureaucratic, standardized, oppressive and authoritarian, why don't we allow more and more people to be free? (Cott, 1995, p. 114)

Sontag did strongly advocate the establishment of a multiple-value social system which, she argues, would consist not only of a mainstream value system but of one or more than one minor value systems. The inceptive stage of her literary career had already seen her infatuated with the philosophic concept that diversity is one of the cardinal attributes intrinsic in all entities in the universe. Her endorsement of the concept remained staunch throughout her life and can be borne out by the Sontag corpus, including her cinematic production.

\section{Conclusion}

Aesthetics and morality are the two key terms appearing in Sontag's essayistic writing; meanwhile, conflict and coexistence of the two terms constitute an implicit clue in her fictional creation, albeit some critics criticize that she has been waggling between the two poles. They argue her earlier fictional works are embodied with the typical characteristics of European experimental fiction; interest she displayed in the form of fiction goes beyond her concern over moral evaluation involved. David Rieff, the only son of Sontag, identifies her mother with "the Moralist Aesthete" and "the Aesthete Moralist", and claims "she was torn between aestheticism and moralism, beauty and ethics. Any intelligent reader of hers will see the force of this, but I think a shrewder account would emphasize their inseparability" (AST, 2007, p. xv) ${ }^{3}$. There is also a remarkable consistency of her ideas on aesthetics and morality even from her earlier works. Her earliest novel, $T B$, is definitely an experimental work embodying the symbiosis of aesthetics and morality, but she deliberately endued aesthetics, as one opposite of the symbiotic relationship, with an extravagant overgrowth to the overpowering of and then to the shattering of morality, as the other opposite of the symbiotic unity.

Confronting with the serious crisis in fictional history, the mimesis of outside and inside worlds in conventional fiction is distained by the experimental writers in the 1960s. It is against such a historical background that metafiction as a literary genre came into being. It has ironized authenticity that realistic and modernist fictional works have highlighted, by intentionally mixing up the boundary of reality and fictionality, creation and criticism. It exploits the indeterminacy of text on the level of language and plot, forcing its readers to revise their rigid preconception based on literary and social conventions, by playing off earlier paradigm and thus defeating readers' expectations for the conventional reading habit. Metafiction and its various metamorphoses do recover fiction from the crisis of its decline. Sontag's endeavor to write her fictional works was triggered by the insidious ambience engulfing literary circles in America in the 1960s. Therefore that she resorted at that time to blazing her path into the wonderland of metafictional writing could only be a matter-of-course. Her resentment against the rampancy of Freudianism-based or Marxism-based interpretation of text operated as one of the vital factors that swerved her in the direction of upgrading the artistry peculiar to metafictional writing. Technique such as sporting the game of language, involving a writer and his readers in person-to-person conversation, featured the keen initiative taken by Sontag in her drive for innovating the technical aspect of metafictional production. The authority of a writer was denounced; and the gist of a fictional

\footnotetext{
${ }^{3}$ At the Same Time is the title of an essay by Sontag, which is anthologized in a posthumously-published essay collection edited by Paolo Dilonardo and Anne Jump. By way of paying homage to his mother, David Rieff, Sontag's only son, wrote a preface to the collection.
} 
work could be arbitrarily illustrated.

Preference for fictionality that metafiction has revealed does not mean that there are no realistic components in metafiction, or metafiction no longer reflects social life. Metaficiton, as a subgenre of fiction, cannot completely ignore or abandon the realistic conventions. As Patricia Waugh has elucidated:

Metafiction does not abandon "the real world" for the narcissistic pleasures of imagination, what it does is to re-examine the conventions of realism in order to discover-through its self-reflection-a fictional form that is culturally relevant and comprehensible to contemporary reader. (Waugh, 1984, p. 18)

Content in metafictional novel no longer occupies as important a position as that in realistic novels, but it does not mean metafictional novels has no social bearing or does not invite moral reflection. Although Sontag in $T B$ concentrates on the construct of metafictional form, morality is not the focus of her discussion; it does not represent that there is no moral inclination in this fictional work. More accurately, when she was devoted to the conception of the novel, she unconsciously reserved her suspicion of Hypperlyte's solipsistic life in that she intentionally arranged him to go back to commonness by giving up dreaming. As for such an anti-intellectual finality, Sontag was not satisfied either; therefore, she could not help ridiculing him for his reconciliation. With the double negation toward Hippolyte's attitude to dreaming, Sontag, in effect, delivers her expectation for the freedom of intellectual behaviors.

To sum up, the most pronounced characteristic of formalist aesthetics consists in highlighting the outward form of the novel more than giving prominence to the moral concern. What is preponderantly discussed in the first two sections of this essay is how Sontag works to have the principle of formalist aesthetics clearly manifested in $T B$ by bringing about fictionality pertaining to the metafiction and dissolution of certainty of Hippolyte's dream narrative. The third section of this essay elaborates not only on the way in which Sontag avails herself of irony as a means for giving expression to her implied moral concern but also on how Sontag's overuse of formalist aesthetic device entails an eclipse of the symbiotic unity formed of both aesthetic appeal and moral norm actually tangible and traceable in the text of $T B$. Therefore, it is fair to say the symbiotic relationship between aesthetics and morality has been formulated since the beginning of her fictive creation, although the emphasis on style in TB seems to convey a confusing message that she is obsessed in the construction of formal aesthetics and pay no heed to social issues. In effect, moral component has never receded from her fictive creation. It is just because her overemphasis on recovering a new sensibility of art easily strikes some credulous readers an impression that she disregards moral position that a novelist should stick to in social life. She implicitly revealed her disagreement with the suppression of the intellectual behaviors by having the marginal minds transformed so as to fit in with the criterion of conventional mores.

\section{References}

Adam, R. M. (17 Oct. 1963). Nacht und Tag. New York Review of Books.

Bellamy, J. D. (1995). Susan Sontag. In Conversation with Sontag (pp. 35-48). L. Poague, (Ed.). Jackson: University Press of Mississippi.

Cott, J. (1995). Susan Sontag: The rolling stone interview. In Conversation with Sontag (pp. 106-136). L. Poague, (Ed.). Jackson: University Press of Mississippi.

Frakes, J. R. (22 Sept. 1963). Where dreaming is believing. New York Herald Tribune Book Week.

Podhoretz, N. (1968). Making it. London: HarperCollins.

Rieff, D. (2007). Foreword. In At the same time: Essays and speeches (pp. xi-xvii). By Susan Sontag. P. Dilonardo and A. Lump, (Eds.). New York: Farrar, Straus, Giroux. 
Rollyson, C. (2001). Reading Susan Sontag: A critical introduction to her work. Chicago: Ivan R. Dee, Publisher.

Stern, D. (8 Sept. 1963). Life becomes a dream. New York Times.

Sontag, S. (1963). The benefactor. New York: Farrar, Straus, Giroux.

Sontag, S. (2007). Foreword. In The benefactor (pp. 1-3). (J. W. Yao, Trans.). Shanghai: Shanghai Translation Publishing House.

Sontag, S. (1966a). Against interpretation and other essays. New York: Farrar, Straus, Giroux.

Sontag, S. (1966b). A note and some acknowledgments. In Against interpretation and other essays (pp. ix-xi). New York: Farrar, Straus, Giroux.

Sontag, S. (1966c). Against interpretation. In Against interpretation and other essays (pp. 3-14). New York: Farrar, Straus, Giroux.

Sontag, S. (1966d). On style. In Against interpretation and other essays (pp. 15-36). New York: Farrar, Straus, Giroux.

Sontag, S. (1980). Approaching Artaud. In Under the sign of Saturn (pp. 13-70). New York: Farrar, Straus, Giroux.

Trilling, L. (1978). On the teaching of modern literature. Beyond culture: Essays on literature and learning (Chapter 19). Oxford: Harcourt Brace Jovanovich.

Waugh, P. (1984). Metafiction: The theory and practice of self-conscious fiction. T. Hawkes, (Ed.). London and New York: Methuen. 